\title{
Effects of Pulsed Electric Field on the Viscoelastic Properties of Potato Tissue
}

\author{
Ricardo N. Pereira • Federico Gómez Galindo • \\ António A. Vicente - Petr Dejmek
}

Received: 11 February 2009 / Accepted: 15 June 2009 /Published online: 30 June 2009

(C) Springer Science + Business Media, LLC 2009

\begin{abstract}
We have investigated whether transient permeabilization caused by the application of pulsed electric field would give rise to transient changes in the potato tissue viscoelastic properties. Potato tissue was subjected to nominal field strengths $(E)$ ranging from 30 to $500 \mathrm{~V} / \mathrm{cm}$, with a single rectangular pulse of $10^{-5}, 10^{-4}$, or $10^{-3} \mathrm{~s}$. The changes on the viscoelastic properties of potato tissue during pulsed electric fields (PEF) were monitored through small amplitude oscillatory dynamic rheological measurements. The elastic $\left(G^{\prime}\right)$ and viscous moduli $\left(G^{\prime \prime}\right)$ were measured every $30 \mathrm{~s}$ after the delivery of the pulse and the loss tangent change $(\tan -\delta$ ) was calculated. The results were correlated with measurements of changes on electrical resistance during the delivery of the pulse. Results show a drastic increase of $\tan -\delta$ in the first $30 \mathrm{~s}$ after the application of the pulse, followed by a decrease 1 min after pulsation. This response is strongly influenced by pulsing conditions and is independent of the total permeabilization achieved by the pulse. Our results, supported by similar measurements on osmotically dehydrated control samples, clearly show that PEF causes a rapid change of the viscoelastic properties of the tissue that could be attributed to a partial loss in turgor pressure. This would be an expected consequence of electroporation. The recovery of $\tan -\delta$ to values similar to those before pulsation strongly suggests
\end{abstract}

R. N. Pereira $(\bowtie) \cdot$ F. G. Galindo · A. A. Vicente

IBB - Institute for Biotechnology and Bioengineering,

Centre for Biological Engineering, University of Minho,

Campus de Gualtar,

4710-057 Braga, Portugal

e-mail: rpereira@deb.uminho.pt

P. Dejmek

Department of Food Technology, Engineering and Nutrition, Lund Institute of Technology, Lund University,

P.O. Box 124, 22100 Lund, Sweden recovery of cell membrane properties and turgor, pointing at reversible permeabilization of the cells. A slight increase of stiffness traduced by a negative change of $\tan -\delta$ after application of certain PEF conditions may also give an indication of events occurring on cell wall structure due to stress responses. This study set the basis for further investigations on the complex cell stress physiology involving both cell membrane functional properties and cell wall structure that would influence tissue physical properties upon PEF application.

Keywords Small amplitude oscillatory dynamic rheology . Tan- $\delta$ - Permeabilization · Impedance · Turgor .

Pulsed electric fields

\section{Introduction}

In recent years, there has been an increasing interest in the use of pulsed electric field (PEF) due to its potential to induce non-thermal permeabilization of cell membranes. The external application of an electric field $(\leq 1,000 \mathrm{~V} / \mathrm{cm})$ induces a potential difference across the cytoplasmic membrane for a period long enough (microseconds to milliseconds) to induce pore formation in the plasma membrane. ${ }^{1}$ Depending on the cell properties (i.e., size, conductivity, shape, and orientation) and electropulsation parameters (i.e., field strength, duration, and number of pulses), the application of PEF may cause lethal damage to cells due to irreversible loss of cell membrane permeability properties, leakage of cytoplasmic contents, and lysis. ${ }^{2}$ It is well known that the effective plant tissue disintegration under the PEF treatment can be achieved at moderate electric fields of $200-1,000 \mathrm{~V} / \mathrm{cm}$ and short treatment time within $10^{-4}-10^{-2} \mathrm{~s}^{3}$ However, the application of a low 
intensity treatment at low electric field strength and/or pulse number, though initiating a conductive channel across the membrane, does not necessarily cause irreversible cell rupture. 4 , 5

Reversible electroporation has been reported for potato tissue (after a time of $0.7 \mu$ s for membrane charging and a membrane potential of $1.7 \mathrm{~V}$ a pore is formed), but electrically insulating properties can be recovered within seconds, restoring vitality and metabolic activity. ${ }^{6}$ Depending on the PEF parameters, reversible electro-permeabilization can provide a potential to induce stress responses, such as stress-induced metabolite production. ${ }^{7,8}$

When PEF treatments are given in conditions compatible with irreversible cell damage, it affects the viscoelastic properties of plant tissues. It was demonstrated that PEF treatments may decrease the stiffness of potato tissue to levels similar to those achieved by hyper-osmotic treatment. ${ }^{9}$ Many detailed studies related with textural and rheological effects of PEF in plant tissues are found in the literature. $^{10,11}$ Lebovka et al. $^{12}$ used stress deformation and relaxation tests to measure the effects of PEF and the combination of PEF and mild heating on the texture of carrots, potatoes, and apples, analyzing the rheological behavior of the samples after giving the treatments that caused tissue disintegration. This investigation as well as others in which changes on rheological properties of PEFtreated potatoes are addressed, ${ }^{9}, 13,14$ would deal with a tissue in which cell membranes permeability properties have been damaged with a consequent leakage of cell components. However, based on previous publications of our group, ${ }^{15,16}$ it is expected that when mild electric field treatments are used and the cell membranes have the capacity to recover their functional properties, metabolic responses may create, in a time scale of seconds, a very dynamic cellular system in terms of variations of cell turgor as well as structural changes. Therefore, dynamic rheological measurements during the PEF treatment would provide valuable information on the behavior of tissues under PEF stress.

Texture is a dynamic property influenced by environmental stressors ${ }^{17}$ that provokes physiological responses that might be reflected in changes in turgor pressure and microstructure. ${ }^{18}$ Dynamic changes on turgor are relevant in the case of PEF because opening pores in the cell membrane will result in the efflux and influx of polar molecules. Furthermore, after the pulse application, the resealing process is accompanied by oxidative stress with the consequent production of reactive oxygen species (ROS). ${ }^{19}$ Interestingly, ROS production in PEF-treated potato tissue has been recently associated with a decrease of cell wall porosity, which may influence the viscoelastic properties of the treated tissue. ${ }^{14}$ Therefore, we here have performed dynamic rheological measurements of potato tissue subjected to transient electroporation to get insights into the dynamics of potato tissue viscoelastic properties during and after application of PEF (at different pulse widths and strengths) that might be related with physiological events associated with poration and resealing.

Dynamic mechanical analysis is highly sensitive to changes in the behavior of the cells' mechanical components ${ }^{20}$ being therefore an effective method to evaluate texture changes. It has also the advantage of being a nondestructive test as very small strains are applied on the samples (less than $0.1 \%$ ) over a short time, with minimal physical damages. $^{21,22}$

\section{Materials and Methods}

\section{Raw Material, Handling, and Storage}

Potato tubers (Solanum tuberosum L. cv. Bintje) grown in the south of Sweden were used. The potatoes were harvested and placed in a storage room forming piles of $4.5 \mathrm{~m}$ maximum height. The potatoes were stored at $4{ }^{\circ} \mathrm{C}$ (approximately 100\% RH) in the dark without the addition of sprouting inhibitors. These are conditions routinely practiced by the producer. Potato tubers free from defects, stored under the described conditions for 3 months, were selected at the farm storage facility and transported to our laboratory in plastic bags kept on ice in insulated boxes. The potatoes were then placed in a closed refrigerated chamber at $3^{\circ} \mathrm{C}$ in darkness until use.

\section{Sampling}

Potato tubers were equilibrated to room temperature for approximately $1 \mathrm{~h}$, manually washed and peeled. One slice, $15 \mathrm{~mm}$ thick, was obtained from the center of a single tuber. The slice was oriented perpendicular to the major tuber axis. A rectangular cross-section sample, $15 \mathrm{~mm}$ long and $6.0 \mathrm{~mm}$ wide, was obtained from the phloem parenchyma tissue of the slice using a pair of parallel sharp blades. Immediately after cutting, the sample was rinsed with distilled water and gently blotted with medical wipes to remove the excess of water from the sample surface. Samples were divided in two groups: the first group was treated with electric pulses directly after the sampling in order to characterize PEF-related viscoelastic changes as a function of pulse length, pulse number, and field strength; the other group was osmotically pre-treated prior to the electrical treatment, to evaluate the viscoelastic properties of potato tissue where turgor pressure has been decreased. 
Osmotic Pre-treatment

Potatoes samples were osmotically pre-treated with $0.7 \mathrm{M}$ solution of mannitol for $2.5 \mathrm{~h}$, before PEF application. Electrical treatments and viscoelastic measurements were then performed on untreated and osmotically pre-treated samples as described in the following sections.

\section{Experimental Setup and Electrical Treatment}

The experimental setup for PEF treatment of the samples and measurement of the electrical response and viscoelastic properties is shown in Figure 1. The pulse generator was a Cellect electro-manipulation instrument (BioFusion SCI AB, Lund, Sweden) that was connected to a Stresstech rheometer (Reologica Instruments AB, Lund, Sweden). The rectangular samples were placed in horizontal position between the lower and the upper steel parallel plates of the rheometer $(30 \mathrm{~mm}$ diameter), which were separated $6 \mathrm{~mm}$ from each other. The plates were fixed to the rheometer by a nonconductive material and used as electrodes. The plates were connected in series to a reference resistor $(300 \Omega)$ and to the pulse generator.

Samples were treated as described by Gómez Galindo et al. ${ }^{15}$ at field regimes suggested to induce physiological stress responses on potatoes tissues. Nominal field strengths (E) ranging from 30 to $500 \mathrm{~V} / \mathrm{cm}$, with single rectangular pulses of $10^{-5}, 10^{-4}$, and $10^{-3} \mathrm{~s}$, were delivered axially to the tissue. Osmotically pre-treated samples were subjected to a single $10^{-3} \mathrm{~s}$ pulse in the range of 30 to $500 \mathrm{~V} / \mathrm{cm}$; additionally, a sequence of nine rectangular pulses of $500 \mathrm{~V} / \mathrm{cm}$ of $10^{-3} \mathrm{~s}$ each was also tested. Five measurements were done for each treatment. Control samples were neither osmotically or PEF-treated and only subjected to dynamic rheological measurements.

\section{Measurements}

\section{Electrical Response of the Tissue During the Pulse}

The resistance of the tissue samples during the pulsing period was measured (Figure 1, switch B was turned on) as the potential difference over the reference resistor and was stored and observed on a digital storage oscilloscope (EM621 digital oscilloscope, ETC instruments, Zilina, Slovak Republic) connected to the system. At the last part of the pulse period, the current-time relationship was converted into the "instantaneous" resistance by dividing the applied voltage by the time-dependent current. The resistance of the tissue was then evaluated by subtracting the reference resistance. ${ }^{23}$ The degree of damaged tissue (Eq. 1) was estimated by means of the electrical conductivity disintegration index, $Z:^{24}$

$Z=\frac{\sigma-\sigma_{\mathrm{i}}}{\sigma_{\mathrm{d}}-\sigma_{\mathrm{i}}}$

where $\sigma$ is effective electrical conductivity at different PEF parameters, $\sigma_{\mathrm{i}}$ is the conductivity of intact tissue, and $\sigma_{\mathrm{d}}$ is the sample conductivity corresponding to maximum per-
Fig. 1 Pulsed electric fields: electrical and rheological measurement setup

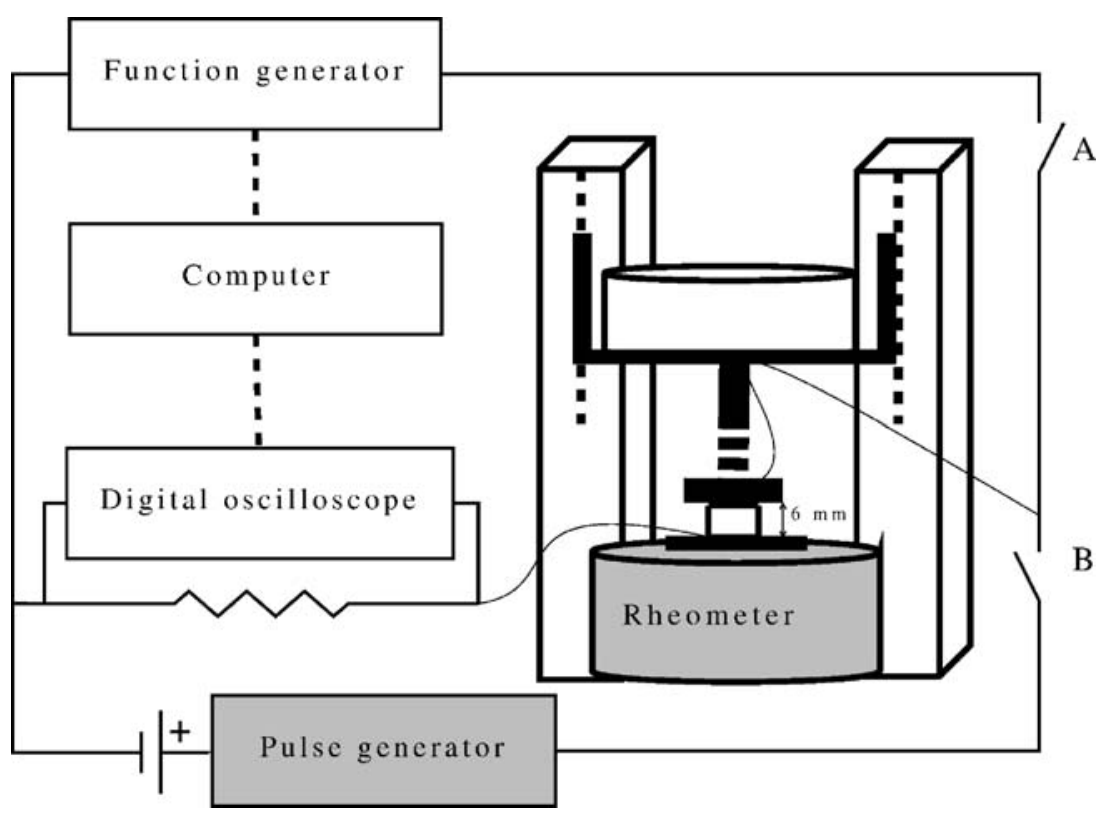


meabilization obtainable by sequence of nine pulses at $E$ and pulse width of $500 \mathrm{~V} / \mathrm{cm}$ and $10^{-3}$, respectively.

\section{Dynamic Rheological Measurements}

Small amplitude oscillatory dynamic rheological measurements were performed on the potato samples before, during, and after the application of the electrical treatment. The potato sample was placed on the lower plate of the rheometer. The upper plate was brought into contact with the sample until a normal force of $1 \mathrm{~N}$ was reached. Measurements of the elastic modulus $\left(G^{\prime}\right)$ and viscous modulus $\left(G^{\prime \prime}\right)$ were recorded in the oscillatory mode as a function of time at intervals of $30 \mathrm{~s}$ and the $\tan -\delta\left(G^{\prime \prime} / G^{\prime}\right)$ was calculated. The oscillation stress amplitude was $0.1 \%$ and the frequency $1 \mathrm{~Hz}$. Stress sweeps were applied to verify that data were acquired within the linear viscoelastic regime. For each PEF treatment, the pulsation was given 150 to $200 \mathrm{~s}$ after the start of the oscillatory measurement. This delay time was taken to the time necessary for the stabilization of the oscillatory measurement parameters before pulse delivering (Figure 2a). Time started to be measured immediately after pulse delivery. The $\tan -\delta$ change $\left(\tan -\delta_{\mathrm{c}}\right)$ during the oscillatory measurement was calculated by subtracting the $\tan -\delta$ values measured at time intervals of $30 \mathrm{~s}$ after pulsation by the initial value of $\tan -\delta$ $\left(\tan -\delta_{\mathrm{i}}\right)$, immediately measured before pulsation (Eq. 2). The result of the calculation is reported in Figure $2 b$, where the values corresponding to the initial stabilization of the oscillatory measurements have been subtracted.

$\tan \delta_{\mathrm{c}}=\tan \delta-\tan \delta_{\mathrm{i}}$

\section{Pre- and Post-pulse Electrical Measurement}

Sample impedance was measured prior to PEF treatment and $30 \mathrm{~s}$ to 2 min after PEF with a sinusoidal voltage $\left(V_{\mathrm{s}}\right)$ of $5 \mathrm{~V}$ and $1 \mathrm{kHz}$ (Figure 1; switch A was turned on), as described by Chalermchat, ${ }^{23}$ using a function generator (PC function generator, K8016, Velleman Instruments, Belgium). A reference resistor $\left(R_{\mathrm{f}}\right)$ of $300 \Omega$ was connected in series in the circuit between the samples and the function generator in order to monitor the responding voltage $\left(V_{\mathrm{f}}\right)$ of the whole system. The $V_{\mathrm{f}}$ was monitored and recorded using a digital oscilloscope. The total resistance, or impedance (I), of the tissue after and before PEF treatment was then calculated as in Eq. 3:

$I=R_{\mathrm{f}}\left(\frac{V_{\mathrm{s}}}{V_{\mathrm{f}}}-1\right)$

The effects of PEF treatment on the impedance of the tissues were evaluated throughout the time by calculating

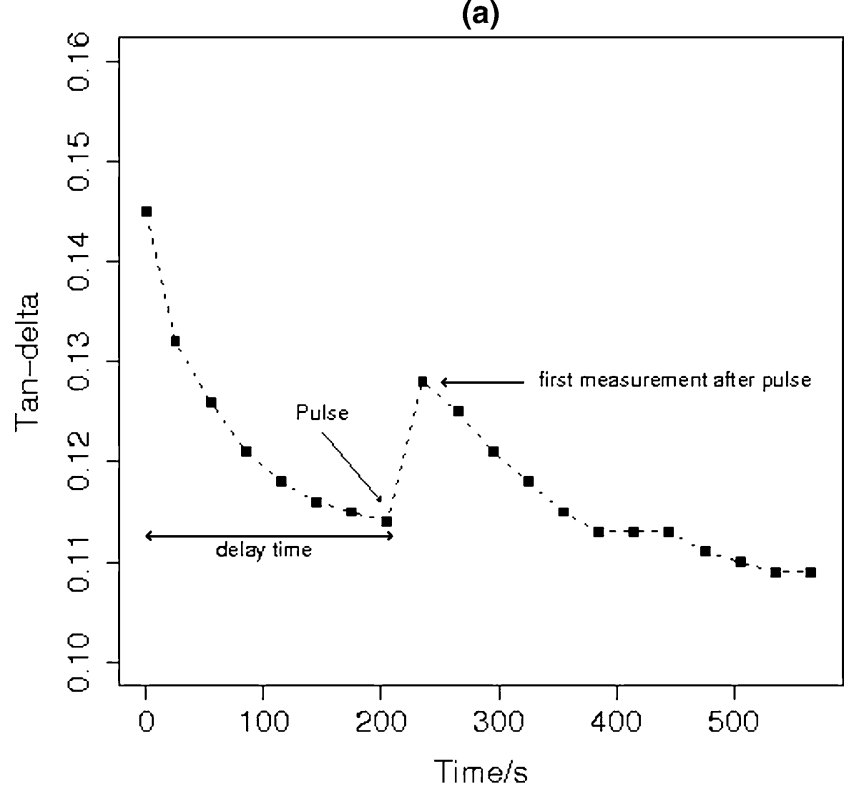

(b)

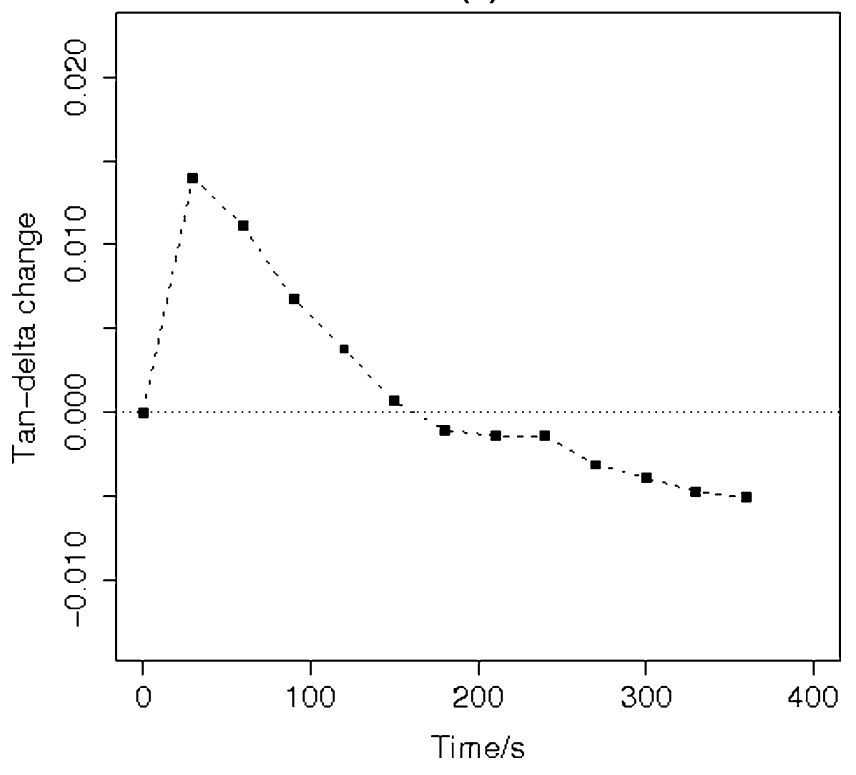

Fig. 2 Example of measurement of $\tan -\delta$ subjected to an electric pulse of $1 \mathrm{~ms}$ and $400 \mathrm{~V} / \mathrm{cm}$ : a PEF was applied (indicated with an arrow in the curve) after stabilization of the oscillatory measurements; $\mathbf{b} \tan -\delta$ change after normalization of peaks to start at the origin, where $\tan -\delta$ values before the pulse were subtracted from the figure

the relative difference $\left(I_{\mathrm{c}}\right)$ between the impedance of the sample measured immediately before pulsing $\left(I_{\mathrm{i}}\right)$ and the impedance measured after pulsing $\left(I_{\mathrm{t}}\right)$ at time intervals of 20 s, using Eq. 4.

$I_{\mathrm{c}}=\left(\frac{I_{\mathrm{t}}-I_{\mathrm{i}}}{I_{\mathrm{i}}}\right)$ 


\section{Results}

Electrical Response of the Tissue During the Delivery of the Pulse

The final electrical resistance of the potato tissues during the delivery of the pulse plotted against the applied $E$ at three different pulse widths $\left(10^{-5}, 10^{-4}\right.$, and $\left.10^{-3} \mathrm{~s}\right)$ is shown in Figure 3. As the applied voltage and the reference resistance are constant and the sample resistance changes during the pulse, the actual field strength experienced by the tissue varies. The initial field strength was within $10 \%$ of the nominal field strength for the samples. In a separate experiment, we found that the contact resistance was negligible. The results obtained for the variation of the total resistance of potatoes tissues as function of $E$ are in good agreement with those previously published. ${ }^{16}$ For pulse widths of $10^{-4}$ and $10^{-5} \mathrm{~s}$, no measurements could be done in the oscilloscope at $E<100 \mathrm{~V} / \mathrm{cm}$ and $<200 \mathrm{~V} / \mathrm{cm}$, respectively. At the $E$ of about $200 \mathrm{~V} / \mathrm{cm}$ and field widths of $10^{-3}$ and $10^{-4} \mathrm{~s}$, the resistance decreased markedly, followed by a slight decrease after $200 \mathrm{~V} / \mathrm{cm}$. At $E$ of 400 and $500 \mathrm{~V} / \mathrm{cm}$, the resistance values at $10^{-3}$ and $10^{-4} \mathrm{~s}$ are nearly the same. For pulse widths of $10^{-5} \mathrm{~s}$, the portion of the curve showing a slower decrease of the resistance was evident only above $400 \mathrm{~V} / \mathrm{cm}$. At $E$ of $500 \mathrm{~V} / \mathrm{cm}$, the resistance value at $10^{-5} \mathrm{~s}$ is only slightly higher than those observed at higher field widths.

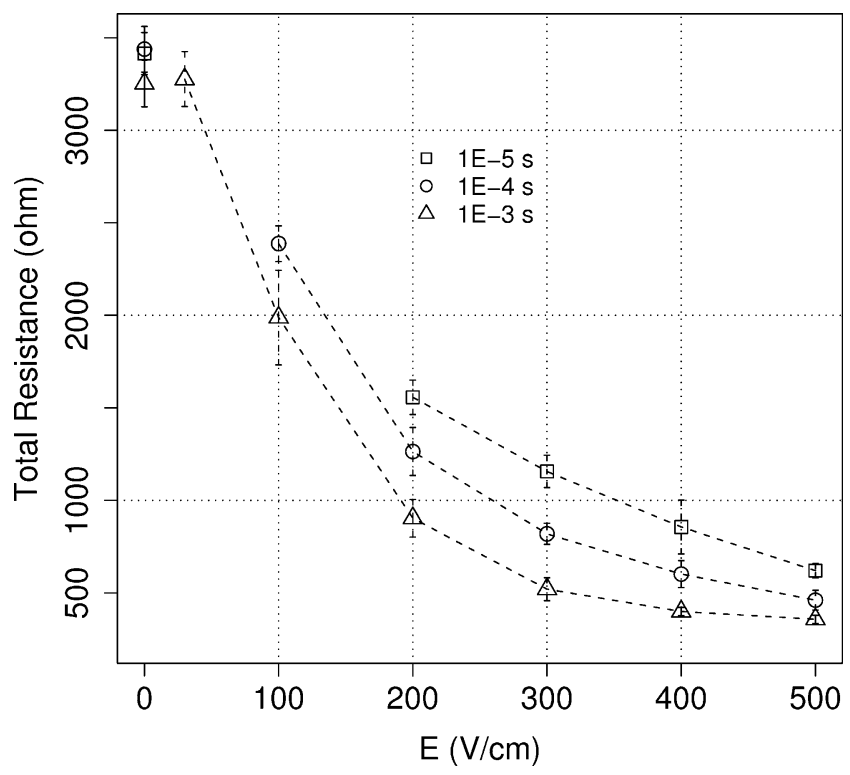

Fig. 3 Total resistance of potato samples during the application of unipolar, rectangular pulses at different nominal field strengths $(E)$ and widths: the error bars represent the standard deviation of the mean of five experiments
Electrical conductivity disintegration degree $(Z)$ versus PEF treatment time at different $E$ is presented in Table 1. Increase of disintegration efficiency during pulse was observed with increase of both pulse duration and $E$. However, the $Z$ value seems to stabilize for longer treatment times, particularly for high field regimes such as $500 \mathrm{~V} / \mathrm{cm}$. These results are in good agreement with the ones obtained by Lebovka et al. ${ }^{19}$ which have reported that a distinctive feature of the observed $Z$ time dependence, at moderate field regimes, is the existence of one or more levels of $Z$ saturation.

\section{Viscoelastic Properties}

The tan- $\delta_{\mathrm{c}}$ during dynamic oscillatory rheological measurements are presented in Figure 4, for PEF treatments of $10^{-5}$, $10^{-4}$, and $10^{-3} \mathrm{~s}$. To facilitate comparison between the treatments, the $\tan -\delta$ values before the pulse have been subtracted and the peaks have been normalized to start at the origin. The ability of the tissue to recover to its original viscoelastic properties has been traduced by $\tan -\delta$ recovery (Figures 5 and 6), which gives the increase and decrease in percentage of $\tan -\delta_{\mathrm{c}}$ after PEF.

The tan- $\delta$ change of tissues osmotically treated alone or in combination with PEF showed negative values. Independent of the pulse conditions applied, $\tan -\delta$ presented a decrease of approximately of $6 \%$ of its initial value at end of the measurement. On the other hand, the viscoelastic response observed on turgid tissues after PEF treatments was strongly influenced by intensity, number, and width of the applied pulse. PEF treatments at pulse widths of $10^{-3} \mathrm{~s}$ and at $E$ below $200 \mathrm{~V} / \mathrm{cm}$ did not cause changes in the tan- $\delta$ values. However, for applied $E$ from 200 to $500 \mathrm{~V} / \mathrm{cm}$, there was an increase of $\tan -\delta$ in the first $30 \mathrm{~s}$ after electropulsation, followed by a decrease during $400 \mathrm{~s}$ of the oscillatory measurement. For example, at $10^{-3} \mathrm{~s}$, the increase in the applied $E$ from 200 to $500 \mathrm{~V} / \mathrm{cm}$, led to an increase of $\tan -\delta$ from $4.6 \%$ to $20 \%$ (Figure 5 ). However, at field regimes of 200,300 , and $400 \mathrm{~V} / \mathrm{cm}, \tan -\delta$ values decreased to the initial values observed before pulse delivery, after 150,240 , and $270 \mathrm{~s}$ of measurement, respectively. The $\tan -\delta$ of samples treated with one single rectangular pulse of $10^{-3}$ and $E$ of $500 \mathrm{~V} / \mathrm{cm}$ did not recover to the initial values $400 \mathrm{~s}$ after pulse delivery.

At pulse width of $10^{-4} \mathrm{~s}$, the tan- $\delta$ increased from $0.4 \%$ to $7.9 \%$ (Figure 6) and presented a faster recover to the original viscoelastic properties than those observed at pulses of $10^{-3} \mathrm{~s}$, independent of field strength intensity; at $E$ between 300 and $500 \mathrm{~V} / \mathrm{cm}, \tan -\delta$ values decreased to the initial value after $120 \mathrm{~s}$ of measurement. Pulses of $10^{-4} \mathrm{~s}$ at $E$ lower than $300 \mathrm{~V} / \mathrm{cm}$, as well as electrical treatments at pulse widths of $10^{-5} \mathrm{~s}$ (only shown in Figure 4), did not promote any changes in $\tan -\delta$. 
Table 1 Disintegration degree (Z) during the application of unipolar, rectangular pulses at different nominal field strengths $(E)$

The error bars represent the standard deviation of the mean of five experiments. Means in columns followed by the same letter are not significantly different $(P>0.05)$

\begin{tabular}{llll}
\hline Nominal field strength, $E(\mathrm{~V} / \mathrm{cm})$ & \multicolumn{3}{l}{$Z$ degree } \\
\cline { 2 - 4 } & \multicolumn{2}{l}{ Pulse duration (s) } & \\
\cline { 2 - 4 } & $10^{-5}$ & $10^{-4}$ & $10^{-3}$ \\
\hline 200 & $0.12 \pm 0.01 \mathrm{a}$ & $0.15 \pm 0.03 \mathrm{a}$ & $0.20 \pm 0.03 \mathrm{a}$ \\
300 & $0.24 \pm 0.04 \mathrm{a}$ & $0.31 \pm 0.03 \mathrm{a}, \mathrm{b}$ & $0.44 \pm 0.07 \mathrm{~b}$ \\
400 & $0.43 \pm 0.11 \mathrm{~b}$ & $0.54 \pm 0.09 \mathrm{~b}, \mathrm{c}$ & $0.66 \pm 0.04 \mathrm{c}$ \\
500 & $0.62 \pm 0.05 \mathrm{c}$ & $0.80 \pm 0.13 \mathrm{~d}, \mathrm{e}$ & $0.88 \pm 0.06 \mathrm{e}$ \\
\hline
\end{tabular}

Additionally, for the PEF treatments at $200 \mathrm{~V} / \mathrm{cm}$ and $10^{-3} \mathrm{~s}, \tan -\delta$ presented a recovery to values below the initial ones (negative values, see Figure 5), showing a $3 \%$ decrease from the initial value $180 \mathrm{~s}$ after pulse delivery. This tendency was also shown at $E$ ranging from 300 to $500 \mathrm{~V} / \mathrm{cm}$, when pulses of $10^{-4} \mathrm{~s}$ were applied (Figure 6). For all conditions previously reported, the decrease $\tan -\delta$ below initial values $(\sim 3 \%)$ was still noticed at the end of the oscillatory measurements, which took about $400 \mathrm{~s}$.

The maximum tan- $\delta$ change of the peak of the curves was also used to compare the different PEF treatments. Figure 7 shows the results of $\tan -\delta$ maximum obtained at different pulse widths and intensities. Pulse widths of $10^{-5} \mathrm{~s}$, for all applied field strengths, did not produce any kind of peak. At $10^{-4} \mathrm{~s}$, at $E$ beyond $200 \mathrm{~V} / \mathrm{cm}$, an increase in the maximum values of $\tan -\delta$ was noticed. At $10^{-3}$ s, peaks obtained at $E$ above $100 \mathrm{~V} / \mathrm{cm}$ showed a higher increase in the maximum values of $\tan -\delta$ compared with those obtained at $10^{-4} \mathrm{~s}$.

Sample Impedance

Figure 8 summarizes the impedance change of PEF-treated and osmotically pre-treated tissues plotted against time after pulsing. The electrical resistance is reported as the absolute
Fig. 4 Effects of PEF treatment on the $\tan -\delta$ of potato tissue. One single pulse of $10^{-5} \mathrm{~s}$ (empty square), $10^{-4} \mathrm{~s}$ (empty circle), and $10^{-3} \mathrm{~s}$, on turgid (filled circle) and osmotically pre-treated tissue (filled square), was applied at different field strengths. The error bars represent the standard deviation of the mean of five measurements

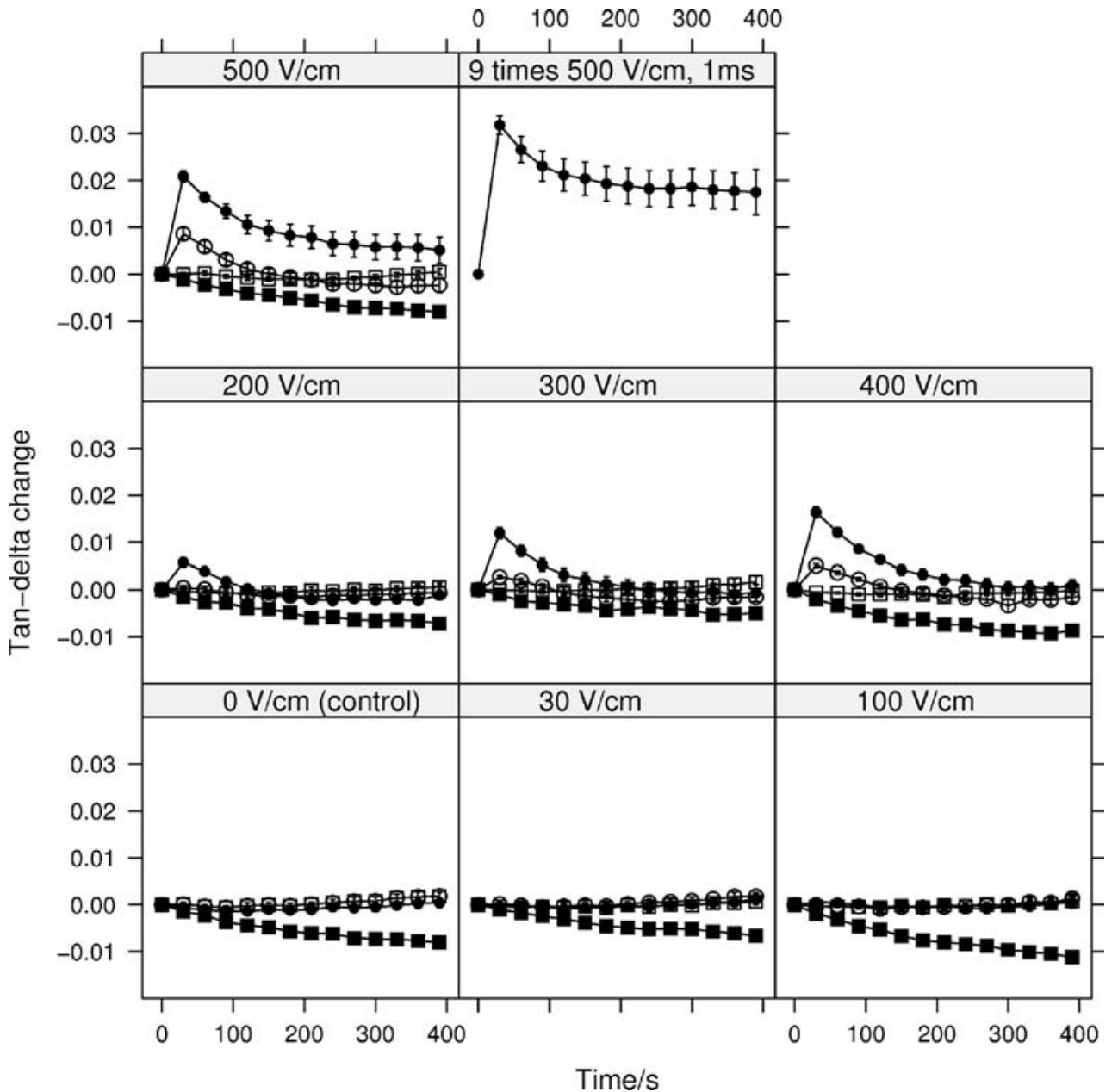

Time/s 

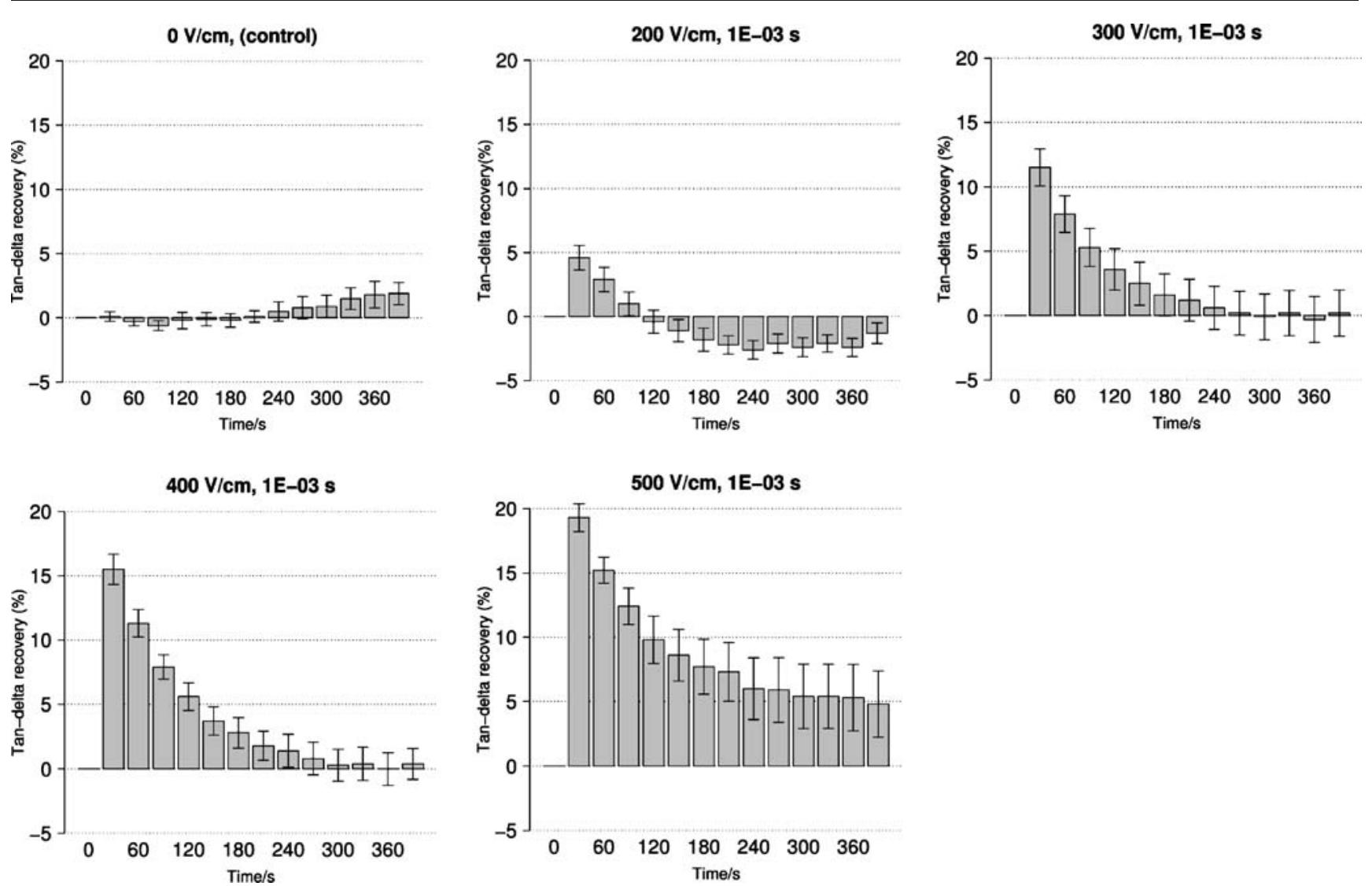

Fig. 5 Tan- $\delta$ percentage recovery observed after a pulse of $10^{-3} \mathrm{~s}$ being applied. The error bars represent the standard error of the mean of five experiments

value of the difference between the resistance at a certain time and the resistance measured before the delivery of the pulse. As a general tendency, changes in impedance were pronounced $30 \mathrm{~s}$ to $1 \mathrm{~min}$ after the application of PEF. Considerable changes on impedance values were not observed after 2 min of measurement.

At pulse widths of $10^{-3} \mathrm{~s}$, the impedance of the potato tissue increased about $25 \%$ and $10 \%$ at $E$ of 200 and $300 \mathrm{~V} / \mathrm{cm}$, respectively. At $E$ of $500 \mathrm{~V} / \mathrm{cm}$, the impedance decreased about $10 \%$, and when nine rectangular pulses of $500 \mathrm{~V} / \mathrm{cm}$ were applied, a decrease of $30 \%$ was observed. At pulse widths of $10^{-4} \mathrm{~s}$, the impedance increased from about $13 \%$ to $30 \%$ at $E$ ranging from 200 to $500 \mathrm{~V} / \mathrm{cm}$. The increase of impedance was also observed at pulse widths of $10^{-5} \mathrm{~s}$, showing an increase from $5 \%$ to $20 \%$ for the $E>200 \mathrm{~V} / \mathrm{cm}$.

\section{Discussion}

The results presented here show the dynamic viscoelastic behavior of potatoes subjected to mild electric field treatments. Interestingly, for pulse widths of $10^{-3}$ and $10^{-4} \mathrm{~s}$, the fast, initial increase in $\tan -\delta$ was higher with increasing of $E$ (Figure 4). These effects were not noticed when the same
PEF treatments were applied at $E$ below $200 \mathrm{~V} / \mathrm{cm}$ which agrees with previous reports showing that reversible cell membrane damage is caused at $E>200 .^{4}$ This sudden decrease in the stiffness of the samples might be attributed to a partial loss in turgor pressure. In support of this idea, the application of PEF on the partially dehydrated tissues, where turgor pressure has been osmotically decreased, did not affect the $\tan -\delta$ values for all the applied field regimes (Figure 4). Results plotted in Figures 5 to 7 showed that this response is strongly influenced by the intensity and width of the pulse. Particularly, for $E$ above $400 \mathrm{~V} / \mathrm{cm}$ and pulse widths of $10^{-3}$ and $10^{-4} \mathrm{~s}$, it is interesting to note that the observed levels of electroporation were nearly the same (Figure 3). Moreover, it was observed that at certain PEF conditions, for different values of $Z$, the PEF-treated tissue presented the same viscoelastic response; for example, potato tissues disintegrated by PEF to levels of $Z=0.5$ (Table $1, E=400 \mathrm{~V} / \mathrm{cm}$, pulse width of $10^{-4} \mathrm{~s}$ ) and $Z=0.2$ (Table $1, E=200 \mathrm{~V} / \mathrm{cm}$, pulse width of $10^{-3} \mathrm{~s}$ ) presented the same maximum value of $\tan -\delta$ (Figure 7) and recovery of its viscoelastic properties. This suggests that the viscoelastic response is independent of the permeabilization achieved by the pulse. This observation is more obvious when the pulse width of $10^{-5} \mathrm{~s}$ was applied, where a drastic 
$0 \mathrm{~V} / \mathrm{cm}$, (control)

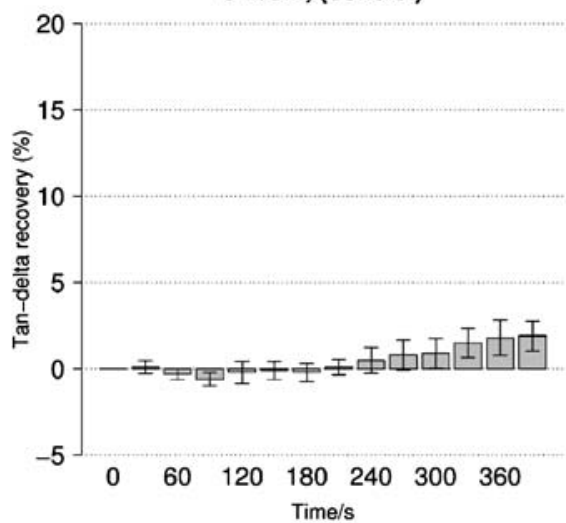

$400 \mathrm{~V} / \mathrm{cm}, 1 \mathrm{E}-04 \mathrm{~s}$

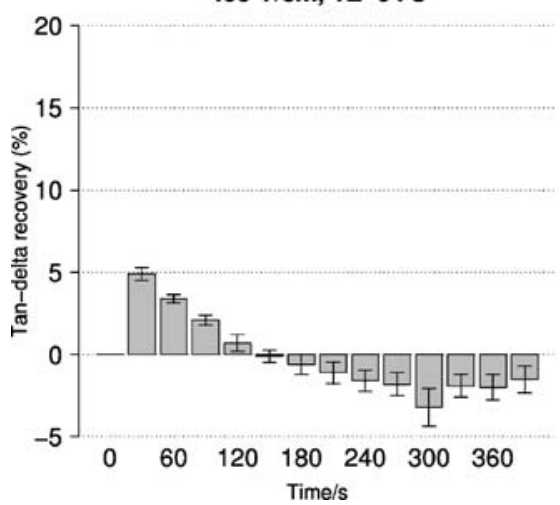

$200 \mathrm{~V} / \mathrm{cm}, 1 \mathrm{E}-04 \mathrm{~s}$

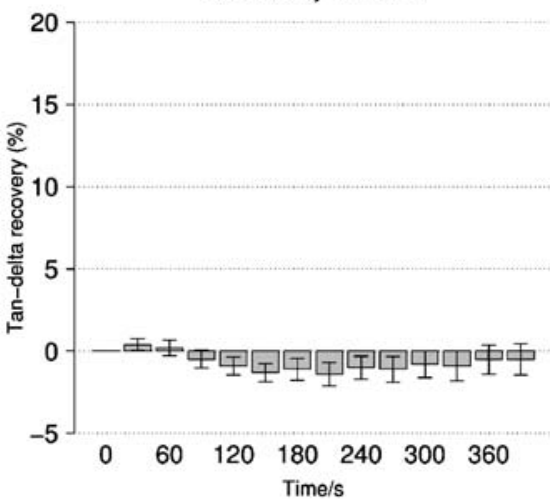

$500 \mathrm{~V} / \mathrm{cm}, 1 \mathrm{E}-04 \mathrm{~s}$

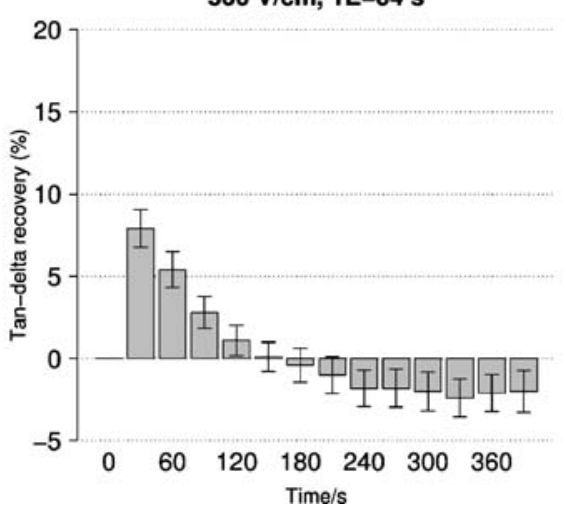

$300 \mathrm{~V} / \mathrm{cm}, 1 \mathrm{E}-04 \mathrm{~s}$

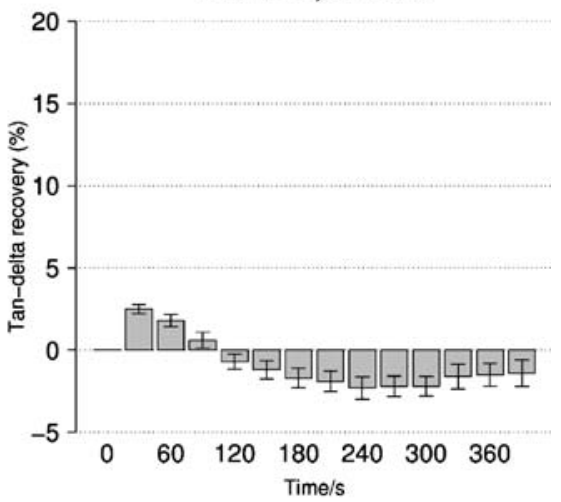

Fig. 6 Tan- $\delta$ percentage recovery observed after a pulse of $10^{-4} \mathrm{~s}$ being applied. The error bars represent the standard error of the mean of five experiments

decrease of the resistance and increase of $Z$ level from 0.1 to 0.6 was not accompanied by a measurable increase on $\tan -\delta$.

Our results strongly suggest that the size and the persistence of the created pores are key factors affecting the increase of $\tan -\delta$. In studies on lipid bilayers, it was shown that the size and the distribution of the pores will depend on the pulsing conditions. Certain PEF conditions may create many small, transient pores (around $1.5 \mathrm{~nm}$ radius) that would relax and reseal in a time scale of nanosecond; ${ }^{25}, 26$ with stronger PEF conditions, the distribution of pore sizes would include larger pores (around $50 \mathrm{~nm}$ radius) which tend to reseal more slowly $\left(>1 \mathrm{~s}\right.$ in some cases) or not at all. ${ }^{26,27}$ It is possible that in both cases the total decrease of resistance is similar. However, the partial loss of turgor pressure would be strongly influenced by the extent of compounds migrating through small or large pores. We can presume that probably these mechanisms of electroporation were reflected by the changes observed in tan- $\delta$ during oscillatory rheological measurements: more intensive PEF treatments may have caused the formation of larger pores in the cell membrane, allowing a faster escape of cell liquid content and thereby a higher increase of $\tan -\delta$ values after pulse delivery.

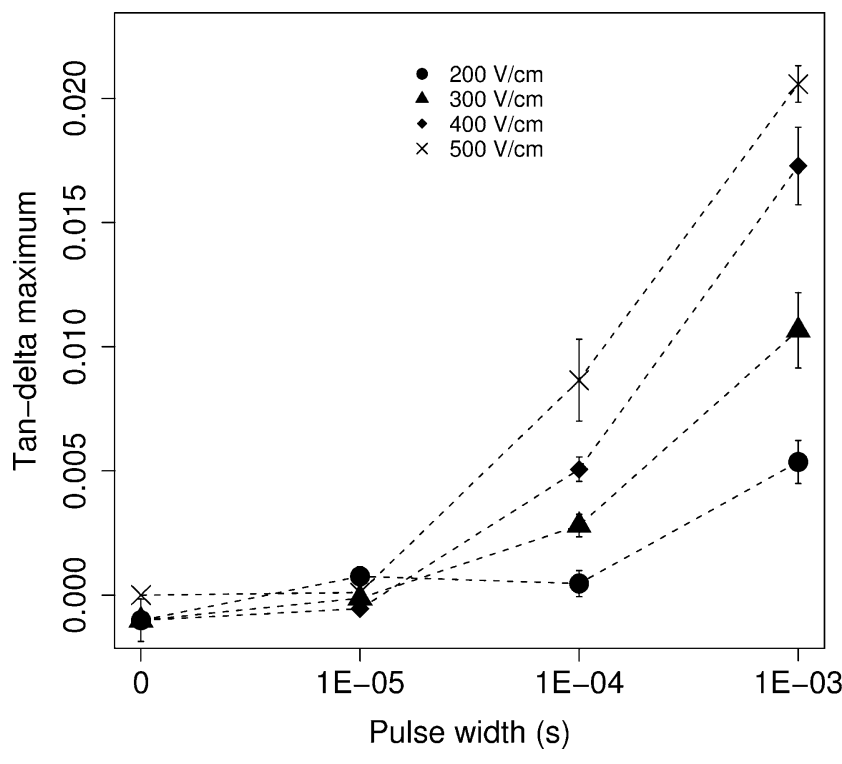

Fig. 7 Effect of pulse strength and width on the maximum value of $\tan -\delta$ measured during small amplitude dynamic viscoelastic measurements. The error bars represent the standard error of the mean of five experiments 
Fig. 8 Change of impedance when one single pulse of $10^{-3} \mathrm{~s}$ (filled circle), $10^{-4} \mathrm{~s}$ (empty circle) and $10^{-5} \mathrm{~s}$ (empty square) were applied on potato tissue at different field strengths. The error bars represent the standard error of the mean of five experiments

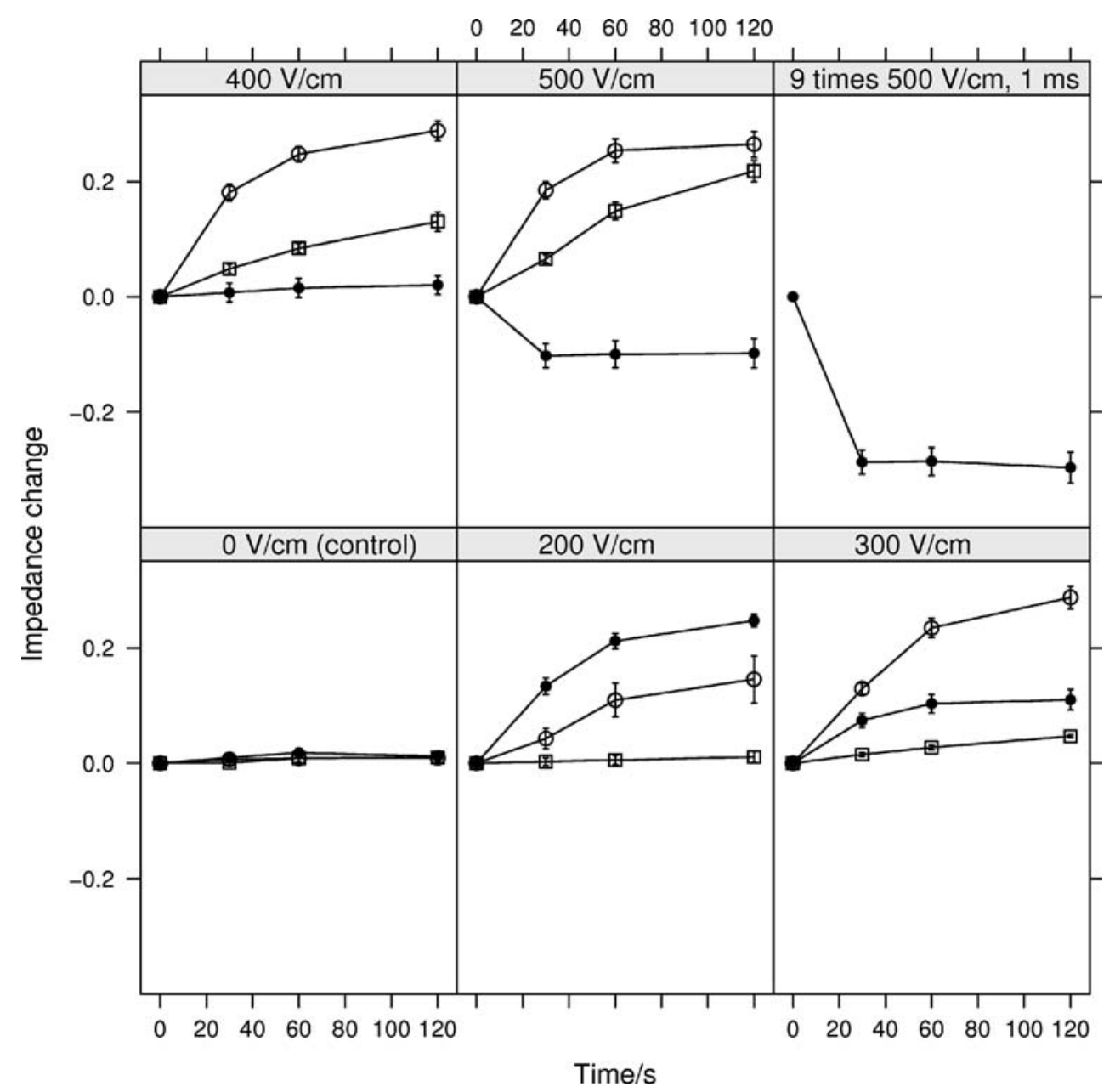

It has been previously shown, using isothermal calorimetry, ${ }^{16}$ that the applied PEF conditions would evade affecting cell viability on the potato tissues. The slow decrease of the $\tan -\delta$ values that follows its fast increase may represent the recovery process of the cells, reabsorbing leaked cellular components and, therefore, recovering their turgor pressure. ${ }^{28}$ In support of this idea, when nine consecutive pulses of high intensity were applied to the tissue with the intention of provoking irreversible permeabilization, the $\tan -\delta$ values did not show recovery. When electrical impedance was used to evaluate the progress of cell membrane permeabilization, a fast increase of the impedance values was observed at certain PEF conditions. Possible reasons for this behavior might be related with the decrease of extracellular volume upon PEF treatment $\mathrm{t}^{29}$ and structural changes on cell wall due to resealing. ${ }^{30}$ However, the most likely explanation for impedance changes may be possibly linked with the roles of ion channels located in the cell membranes. ${ }^{16}, 31$ The $\mathrm{Ca}^{2+}$ channel activation is steeply voltage-dependent. ${ }^{32}$ It has been demonstrated that application of PEF to culture cells of tomato at voltages compatible with cell survival would open voltage-gated calcium-permeable channels elevating cytosolic free $\mathrm{Ca}^{2+} \cdot 33$ The huge $\mathrm{Ca}^{2+}$ concentration difference between $\mathrm{Ca}^{2+}$ stores in cell walls (in concentration in the range of millimolar) and cytosol $(<1 \mu \mathrm{M})^{34}$ would allow an influx of $\mathrm{Ca}^{2+}$ through the opened channels that might substantially decrease the total concentration of ionic species in the apoplast. This cellular event would, therefore, increase the tissue impedance.

The results reported in Figures 4 and 8, with apparently different tendencies, are very useful to illustrate an important principle. Cell membrane-reversible electroporation involves much more that just structural changes in the lipid matrix and leakage of ions but a complex series of events that may include loss of turgor pressure, influx of certain ions through voltage-dependent channels, and/or reabsorption of leaked ions. One or more of these events may take place within the same time scale, and these cannot be uncoupled with measurements of general tissue responses such as the ones used in this investigation.

The idea of different cellular events taking place upon pulsation might also be further illustrated by the $\tan -\delta$ measurements where, under certain PEF conditions, slightly negative values are reported (Figures 5 and 6). In a previous report, Gómez Galindo et al. ${ }^{15}$ suggested that PEF would 
induce oxidative cross-linking of cell wall components. These structural changes would provide architectural strength to the wall. ${ }^{35}$ These PEF-induced changes on the cell wall architecture were taking place within $30 \mathrm{~s}$ after the application of the pulse whereas the negative $\tan -\delta$ values occurred within minutes after the application of the pulse. These results might be the final result of two events: cell membrane permeabilization and consequent partial loss of turgor pressure and strengthening of cell wall, which is being noticed only when the turgor is being recovered. Tan$\delta$ change on partially dehydrated tissues has also shown negative values during small amplitude oscillatory dynamic rheological measurements when compared with control tissues (without any treatment). However, in this case, no differences on viscoelastic behavior were noticed between dehydrated tissues and dehydrated PEF-treated tissues. The negative values observed in osmotically pre-treated samples could have been a result from the effect of the shear stress on completely damaged cells.

\section{Concluding Remarks}

Small amplitude oscillatory dynamic rheological measurements for potato tissue show a sharp initial increase of the $\tan -\delta$ values that could be attributed to a partial loss in turgor pressure. This increase, an expected consequence of electroporation, was strongly dependent on the pulse conditions. At certain PEF conditions, the recovery of the $\tan -\delta$ to values similar to those before pulsation was observed, suggesting the recovery of cell membrane properties and turgor. Moreover, the results show that the viscoelastic response seemed independent from the permeabilization achieved by the pulse, but eventually affected by the different sizes and distribution of the pores created. The increase of stiffness traduced by a negative change of $\tan -\delta$ suggests events occurring on cell wall structure probably due to stress responses induced by PEF.

This study has also resulted in interesting questions regarding different events taking place in the cells upon reversible electroporation. The complex cell stress physiology involving both cell membrane functional properties and cell wall structure would influence the physical properties of the tissue in a pattern that needs to be further explored at the micro- or nanoscale level.

Acknowledgments The authors R.N. Pereira and F. Gómez Galindo gratefully acknowledge their doctoral and post-doctoral grants to the Fundação para a Ciência e Tecnologia (FCT, Portugal).

\section{References}

1. J. Weaver, Electroporation of cells and tissues. IEEE Trans Plasma Sci 28(1), 24-33 (2000)

2. K. Aronsson, M. Lindgren, B.R. Johansson, U. Rönner, Inactivation of microorganisms using pulsed electric fields: the influence of process parameters on Escherichia coli, Listeria innocua, Leuconostoc mesenteroides and Saccharomyces cerevisiae. Innovat Food Sci Emerg Tech 2, 41-54 (2001)

3. N.I. Lebovka, N.V. Shynkaryk, E. Vorobiev, Pulsed electric field enhanced drying of potato tissue. J Food Eng 78, 606-613 (2007)

4. M. Puc, S. Corovic, K. Flisar, M. Petkovsek, J. Nastran, D. Miklavcic, Techniques of signal generation for electropermeabilization. Survey of electropermeabilization devices. Bioelectrochemistry 64, 113-124 (2004)

5. S. Töpfl, Pulsed electric fields (PEF) for permeabilization of cell membranes in food and bioprocessing - applications. Process and equipment design and costs analyses, Ph.D. Dissertation thesis. (Berlin, 2006).

6. A. Angersbach, V. Heinz, D. Knorr, Effects of pulsed electric fields on cell membranes in real food systems. Innovat Food Sci Emerg Tech 1, 135-149 (2000)

7. H. Dörnenburg, D. Knorr, Monitoring the impact of high pressure processing on the biosynthesis of plant metabolites using plant cell cultures. Trends Food Sci Technol 9, 355-361 (1998)

8. N.I. Lebovka, M.P. Kupchik, K. Sereda, E. Vorobiev, Electrostimulated thermal permeabilization of potato tissues. Biosyst Eng 99, 76-80 (2008)

9. M. Fincan, P. Dejmek, Effect of osmotic pre-treatment and pulsed electric field on the viscoelastic properties of potato tissue. J Food Eng 59, 169-175 (2003)

10. N.I. Lebovka, I. Praporscic, S. Ghnimi, E. Vorobiev, Temperature enhanced electroporation under the pulsed electric field treatment of food tissue. J Food Eng 69, 177-184 (2005)

11. M.I. Bazhal, M.O. Ngadi, G.S.V. Raghavan, D.H. Nguyen, Textural changes in apple tissue during pulsed electric field treatment. J Food Sci 68, 249-253 (2006)

12. N.I. Lebovka, I. Praporscic, E. Vorobiev, Effect of moderate thermal and pulsed electric field treatments on textural properties of carrots, potatoes and apples. Innovat Food Sci Emerg Tech 5(1), 9-16 (2004)

13. K.A. Taiwo, A. Angersbach, D. Knorr, Influence of high intensity electric field pulses and osmotic dehydration on the rehydration characteristics of apple slices at different temperatures. J Food Eng 52, 185-192 (2002)

14. P. Arevalo, M.O. Ngadi, M.I. Bazhal, G.S.V. Raghavan, Impact of pulsed electric fields on the dehydration and physical properties of apple and potato slices. Dry Technol 22(5), 1233-1246 (2004)

15. F. Gómez Galindo, P. Vernier, P. Dejmek, A. Vicente, M. Gundersen, Pulsed electric field reduces the permeability of potato cell wall. Bioelectromagnetics 29, 296-301 (2008)

16. G. Galindo, L.P. Wadsö, A. Vicente, P. Dejmek, Exploring metabolic responses of potato tissue induced by electric pulses. Food Biophys 3(4), 352-360 (2008)

17. F. Gómez Galindo, D. Vaughan, W. Herppich, M. Smallwood, M. Sommarin, V. Gekas, I. Sjöholm, Influence of cold acclimation on the mechanical strength of carrot (Daucus carota L.) tissue. Eur J Hortic Sci 69, 229-234 (2004)

18. W.B. Herppich, H. Mempel, M. Geyer, Drought- and low temperature-acclimation in carrot (Daucus carota L.) roots. J Appl Bot 75, 138-143 (2001)

19. J. Teissié, M. Golzio, M. P. Rols, Mechanisms of Cell membrane electropermeabilization: a mini review of our present (lack of ?) 
knowledge. BBA-General Subjects Special Issue: Biophysics Complex Systems, 1724(3), 270-80, (2005)

20. R. Bu-Contreras, M.A. Rao, Review: dynamic rheological behaviour of heated potatoes. Food Sci Technol Int 8(1), 3-10 (2002)

21. S. Gunasekaran, M. Mehmet Ak, Dynamic oscillatory shear testing of foods-selected applications. Trends Food Sci Technol 11, 115-127 (2000)

22. P. Varela, A. Salvador, S. Fiszman, Changes in apple tissue with storage time: rheological, textural and microstructural analysis. J Food Eng 78, 622-629 (2007)

23. Y. Chalermchat, Effects of pulsed electric fields on plant tissue, Ph.D. Dissertation thesis, (Lund University, 2005)

24. N.I. Lebovka, M.I. Bazhal, E. Vorobiev, Estimation of characteristic damage time of food materials in pulsed-electric fields. J Food Eng 54, 337-346 (2002)

25. R.P. Joshi, Q. Hu, K.H. Schoenbach, Simulation of electroporation dynamics and shape deformations in biological cells subjected to high voltage pulses. IEEE Trans Plasma Sci 30, 1536-1546 (2002)

26. Z. Ji, S. Kennedy, J.H. Booske, S.C. Hagness, ?Experimental studies of persistent poration dynamics of cell membranes induced by electric pulses. IEEE Trans Plasma Sci 34, 1416-1424 (2006)

27. F. Ryttsén, C. Farre, C. Brennan, S. Weber, K. Nolkrantz, K. Jardemark, D. Chiu, O. Orwar, Characterization of single-cell electroporation by using patch-clamp and fluorescence microscopy. Biophys J 79, 1993-2001 (2000)
28. R. Arora, J.P. Palta, A loss in the plasma membrane ATPase activity and its recovery coincides with incipient freeze-thaw injury and postthaw recovery in onion bulb scale tissue. Plant Physiol 95, 846-852 (1991)

29. L.F. Ruis-Heutinck, B. Savenije, F. Postema, A.V. Voorst, E. Lambooij, J. Korf, Impedance recordings to determine change in extracellular volume in the brain following cardiac arrest in broiler chickens. Poult Sci 77, 1422-1427 (1998)

30. M. Khine, C. Ionescu-Zanetti, A. Blatz, L.-P. Wang, L.P. Le, Single-cell electroporation arrays with real-time monitoring and feedback control. Lab Chip 7, 457-462 (2007)

31. M. Pavlin, M. Kandušer, M. Reberšek, G. Pucihar, F.X. Hart, R. Magjarević, D. Miklavčič, Effect of cell electroporation on the conductivity of a cell suspension. Biophys J 88(6), 4378-4390 (2005)

32. E. Peiter, F.J.M. Maathuis, L.N. Mills, H. Knight, J. Pelloux, A.M. Hetherington, D. Sanders, The vacuolar $\mathrm{Ca}^{2+}$-activated channel TPC1 regulates germination and stomatal movement. Nature 434, 404-408 (2005)

33. V.L. Link, M.G. Hofmann, A.K. Sinha, R. Ehness, M. Strnad, T. Roitsch, Biochemical evidence for the activation of distinct subsets of mitogen activated protein kinases by voltage and defense related stimuli. Plant Physiol 128, 271-281 (2002)

34. I.I. Pottosin, G. Schönknecht, Vacuolar calcium channels-review article. J Exp Bot 58(7), 1559-1569 (2007)

35. F. Gómez Galindo, E. Bråthen, S. Knutsen, M. Sommarin, V. Gekas, I. Sjöholm, Changes in the carrot cell wall during storage. Food Res Int 37, 225-232 (2004) 